\title{
Comparative Evaluation of Intrathecal Dexmedetomidine and Fentanyl with Hyperbaric Bupivacaine for Post-Operative Analgesia in Lower Abdominal Surgeries
}

\author{
Arun Kumar Saxena', Sapna Singh ${ }^{1}$, B.L. Mathur ${ }^{3}$, Neena Rungta ${ }^{2}$ \\ ${ }^{1}$ Assistant Professors, Department of Anaesthesiology JNU Medical college Jaipur, ${ }^{2}$ Professor, Department of Anaesthesiology JNU Medical College \\ Jaipur, ${ }^{3}$ Professor and Head, Department of Anaesthesiology JNU Medical College Jaipur.
}

\section{Abstract}

Background: Spinal anaesthesia is the fastest and most reliable form of regional anaesthesia. Additions of intrathecaly adjuvants are useful for prolonging the spinal anaesthesia effects. Subjects and Methods: The Patients were divided in three groups; Group C (control group) =

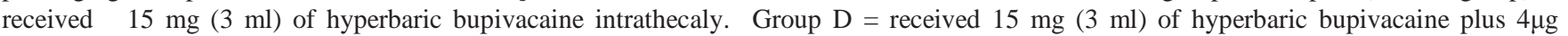
Dexmedetomidine intrathecally. Group F = received Hyperbaric Bupivacaine $15 \mathrm{mg}(3 \mathrm{ml})$ plus $25 \mu \mathrm{g}$ fentanyl intrathecally. Results: For the total duration of sensory block p- value is 0.000003 , which is less than $0.05(\alpha)$ and is highly significant. From the above p - value and scheffe post hoc test we conclude that the Bupivacaine + Dexmedetomidine has prolonged duration of sensory block as compared to bupivacaine alone and in combination with fentanyl. For the motor block p- value is 0.000000 and is less than $0.05(\alpha)$. It is highly significant. For the demand of Analgesic p-value is 0.0000001 and is less than $0.05(\alpha)$ i.e. there is highly significant difference between them. Conclusion: Intrathecal Dexmedetomidine used as an adjuvant to bupivacaine in spinal block seems to be a good alternative to intrathecal fentanyl as it produces early onset and prolonged duration of sensory and motor block without significant haemodynamic alteration and side effects.

Keywords: Dexmedetomidine, Fentanyl and Bupivacaine.

Corresponding Author: Dr. Sapna Singh, Department of Anaesthesiology JNU Medical College Jaipur

Received: July 2019

Accepted: July 2019

\section{Introduction}

Spinal anaesthesia is the fastest and most reliable form of regional anaesthesia. Additions of intrathecaly adjuvants are useful for prolonging the spinal anaesthesia effects. Fentanyl is most widely used adjuvant intrathecally but is associated with side effects like respiratory depression and pruritus. ${ }^{[1]}$ Another neuraxial adjuvant, Dexmedetomidine is highly selective $\alpha 2$-agonist. By virtue of its effect on spinal $\alpha-2$ receptors, it mediates its analgesic effect. It provides adequate intraoperative and postoperative analgesia with stable hemodynamic conditions and minimal side effects. ${ }^{[2]}$ Hence, the present study is undertaken to compare and evaluate the effects of dexmedetomidine and fentanyl as adjuvants to bupivacaine in spinal anaesthesia.

\section{Subjects and Methods}

This study was carried out at JNUIMSRC Jaipur after approval from the Hospital Ethical Committee and written informed consent from the patients. ASA grade I or II patients of either sex, aged 18 to 60 years, scheduled for lower abdominal and lower limb surgery were included in the study.
Patients presenting with known contra indications to spinal anaesthesia, pregnant patients, Patients on therapy with adrenergic receptor antagonist, calcium channel blocker, and/or ACE inhibitor, with history of heart block or dysarrythmia, hypersensitivity to any of the study drugs, who refused to consent to be part of study were excluded from the study.

The Patients were divided in three groups.

Group C (control group) = received $15 \mathrm{mg}(3 \mathrm{ml})$ of hyperbaric bupivacaine intrathecaly.

Group D = received $15 \mathrm{mg}$ ( $3 \mathrm{ml}$ ) of hyperbaric bupivacaine plus $4 \mu \mathrm{g}$ Dexmedetomidine intrathecally.

Group $\mathrm{F}=$ received Hyperbaric Bupivacaine $15 \mathrm{mg}(3 \mathrm{ml})$ plus $25 \mu \mathrm{g}$ fentanyl intrathecally.

Preloading was done with Ringer lactate solution $(10 \mathrm{ml} / \mathrm{kg}$ body weight). Routine monitoring included non invasive blood pressure (NIBP), ECG, heart rate and pulse oximetry. All patients received supplemental oxygen via mask $(31 / \mathrm{min})$

After proper aseptic conditions, spinal anaesthesia was given at the level of L3-L4 interspace in sitting position using a midline approach by a $25 \mathrm{G}$ Quincke spinal needle. The drug was injected slowly over 10-15 seconds with the bevel of the needle pointing upwards and all patients were made supine. 
The intrathecal drug formula was prepared by a separate anaesthesiologist under strict aseptic conditions. The anaesthesiologist who administered anaesthesia was blinded to the group allocation. After administering anaesthesia the vital signs of the patient were recorded. Vitals were recorded every 2 minutes up to the 10th minute and every 5 minutes thereafter up to 20 minutes. Beyond 20 minutes the vitals were recorded every 20 minutes till the time of discharge from PACU (Post Anaesthesia Care Unit).The sensory dermatome level was assessed by loss of pin prick sensation to a $23 \mathrm{G}$ hypodermic needle.

The motor dermatome level was assessed according to the Bromage Scale. ${ }^{[3]}$

- $\quad$ Bromage 0-Patient able to move hip, knee and ankle.

- Bromage 1- Patient unable to move hip, but able to move knee and ankle.

- Bromage 2- Patient unable to move hip and knee but able to move the ankle.

- $\quad$ Bromage 3-Patient unable to move hip, knee and ankle.

The sensory and motor status was assessed at 2 minutes after the spinal injection then, every 5 minutes for the next 30 minutes and thereafter every 30 minutes until the time to regression of sensory level to dermatome S2 and motor scale to bromage 0 .

Time to reach the sensory block up to highest dermatome level and motor block of bromage 3 level was noted. On achieving T8 sensory blocked level, the surgical procedure was carried out. Then time to regression to dermatome S2 level and time to reach bromage 0 was noted in postoperative care unit. All durations were calculated taking the spinal injection time as time zero. Patient was discharged after the sensory block regresses to S2 level and motor block to bromage 0 .

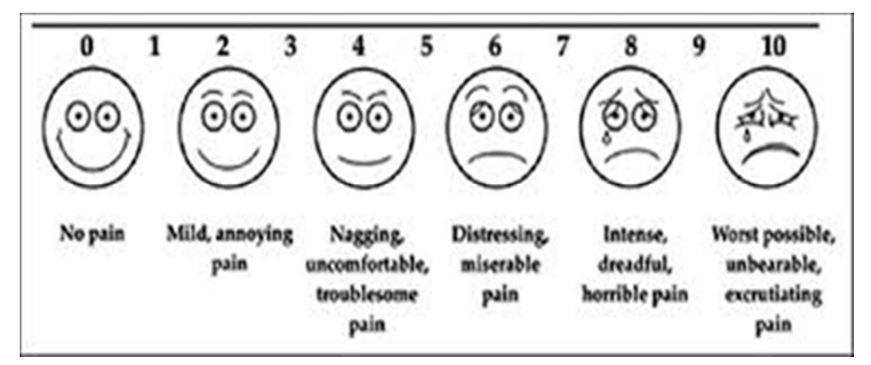

Postoperatively, the pain scoring was done by using visual analog scale $(\mathrm{VAS})(4)(0=$ no pain, $10=$ severe pain $)$, with the vital recordings of the study until the patient was discharged inj diclofenac was given intravenous as rescue analgesia when VAS was greater than 4. Time of administering the first dose of rescue analgesia was taken as the duration of postoperative analgesia due to the adjuvant.

For the purpose of the study hypotension was defined as a decrease in systolic blood pressure more than $30 \%$ of the baseline value or fall below $90 \mathrm{mmHg}$, which was treated by mephenteremine $6 \mathrm{mg}$, i.v. fluids. Bradycardia was defined as heart rate less than $60 / \mathrm{min}$ and was treated with iv atropine $0.6 \mathrm{mg}$.
Results

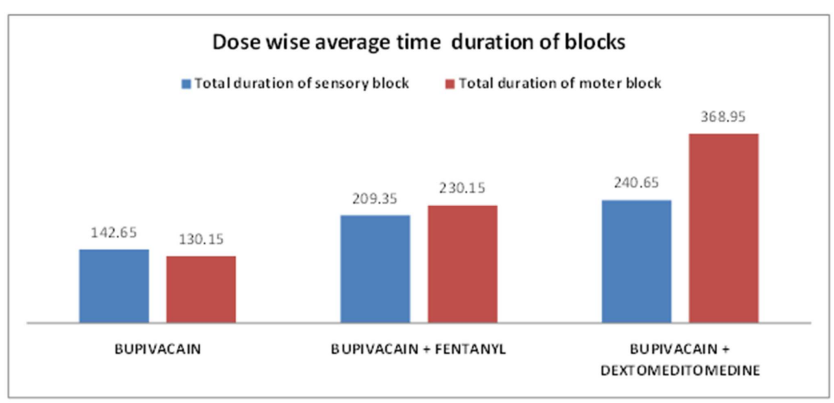

Figure 1: Duration of Block.

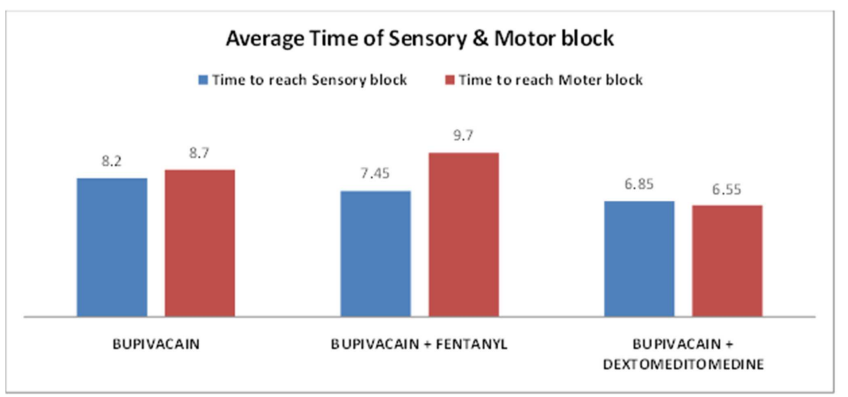

Figure 2: Average time of Sensory \& Motor Block.

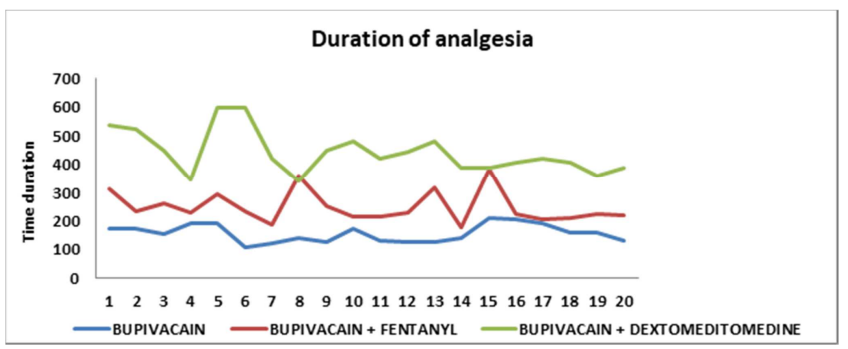

Figure 3: Duration of Analgesia.

\begin{tabular}{l}
\hline Table 1: Patients and surgery characteristics \\
\begin{tabular}{|l|l|l|l|}
\hline Variable & Bupivacaine & $\begin{array}{l}\text { Bupivacaine }+ \\
\text { Fentanyl }\end{array}$ & $\begin{array}{l}\text { Bupivacaine + } \\
\text { Dexmeditomidine }\end{array}$ \\
\hline Age & $46.15 \pm 5.08$ & $39.10 \pm 4.98$ & $31.75 \pm 5.58$ \\
\hline Weight & $64.20 \pm 3.79$ & $63.55 \pm 3.40$ & $65.20 \pm 3.14$ \\
\hline Pulse & $74.05 \pm 3.53$ & $88.65 \pm 5.91$ & $83.30 \pm 5.09$ \\
\hline Blood & $133.1 / 80.4 \pm$ & $134.8 / 83.05 \pm$ & $135 / 81.8 \pm$ \\
Pressure & $4.93 / 2.67$ & $4.54 / 3.52$ & $4.55 / 3.66$ \\
\hline
\end{tabular}
\end{tabular}

Table 2: Block characteristics

\begin{tabular}{|l|l|l|l|}
\hline Variable & Bupivacaine & $\begin{array}{l}\text { Bupivacaine } \\
\text { + Fentanyl }\end{array}$ & $\begin{array}{l}\text { Bupivacaine + } \\
\text { Dexmedetomidine }\end{array}$ \\
\hline $\begin{array}{l}\text { Time to reach T8 } \\
\text { Sensory Block } \\
\text { In min.) }\end{array}$ & $8.2 \pm 0.6$ & $7.5 \pm 1.24$ & $6.85 \pm 1.55$ \\
\hline $\begin{array}{l}\text { Motor Block (In } \\
\text { min.) }\end{array}$ & $8.7 \pm 0.9$ & $9.7 \pm 1.7$ & $8.35 \pm 3.40$ \\
\hline $\begin{array}{l}\text { Total duration of } \\
\text { Sensory Block } \\
\text { In min.) }\end{array}$ & $142.7 \pm 10$ & $209.4 \pm 17.1$ & $241 \pm 21$ \\
\hline $\begin{array}{l}\text { Total duration of } \\
\text { Motor Block (In } \\
\text { min.) }\end{array}$ & $130.2 \pm 9.5$ & $230 \pm 26.6$ & $369 \pm 25$ \\
\hline $\begin{array}{l}\text { Duration of } \\
\text { Surgery }\end{array}$ & $63.1 \pm 16.6$ & $94.4 \pm 17.4$ & $104 \pm 21.5$ \\
\hline $\begin{array}{l}\text { Demand of } \\
\text { Analgesia }\end{array}$ & $156.5 \pm 13.2$ & $250.3 \pm 24$ & $443 \pm 32$ \\
\hline
\end{tabular}


For the total duration of sensory block p- value is 0.000003 , which is less than $0.05(\alpha)$ and is highly significant.

From the above p - value and scheffe post hoc test we conclude that the Bupivacaine + Dexmedetomidine has prolonged duration of sensory block as compared to bupivacaine alone and in combination with fentanyl.

For the motor block p- value is 0.000000 and is less than $0.05(\alpha)$. It is highly significant.

For the demand of Analgesic p-value is 0.0000001 and is less than $0.05(\alpha)$ i.e. there is highly significant difference between them.

\section{Discussion}

Spinal anaesthesia is useful and successful technique in all infraumbilical surgeries. Addition of adjuvants to intrathecal bupivacaine not only improves intraoperative analgesia but also prolongs post-operative analgesia with minimal side effects.

Intrathecal dexmetomidine, $\alpha$ - 2 adenoceptor agonist act by blocking $\mathrm{Na}+$ channel and have antinociceptive action for both somatic and visceral pain.

Fentanyl as an adjuvant when given intrathecally binds to the opioid receptors or other nonspecific binding sites in the spinal cord and rostral migration occurs via the csf to supraspinal sites

Intrathecal Dexmedetomidine as an adjuvant when compared with spinal bupivacaine alone prolongs the sensory block by depressing the release of C-fiber transmitter and by hyper polarization of post synaptic dorsal horn neuron. ${ }^{[5,6]}$

In our study the time of onset for sensory block (T-8 level) was found to be shorter in group D $(6.85 \pm 1.55)$ cases as compared to group F $(7.5 \pm 1.24)$ which was shorter then group C (8.2 \pm 0.6) cases [Table $2 \&$ Figure 2]. These findings are not in concordance with results of $\mathrm{Al}$ Ghanan et al, ${ }^{[7]}$ who observed no difference in onset time in paients receiving Dexmedetomidine (7.5 \pm 7.4$)$, and fentanyl (7.4 \pm 3.3 $\mathrm{mt})$ as adjuvant to isobaric bupivacaine. $(\mathrm{P}=0.95)$.

$\mathrm{Al}$ Ghanem et al, ${ }^{[7]}$ added intrathecal dexmedetomidine $10 \mu \mathrm{g}$ to bupivacaine and found early onset of sensory block to T10 level which is in concordance with our study.

In our study duration of sensory block was increased in group D $(241 \pm 21 \mathrm{~min})$ as compared to group C $(142.7 \pm 10 \mathrm{~min})$ and group $F(209.4 \pm 17.1 \mathrm{~min})$ which is in concordance with study by Shukla et al. ${ }^{[8]}$ In this study, dexmedetomidine $(10 \mu \mathrm{g})$ was added to bupivacaine and it produced early onset and prolonged duration of sensory and motor block with hemodynamic stability and good postoperative analgesia.

Sensory and motor block duration was prolonged with intrathecally $10 \mu \mathrm{g}$ dexmedetomidine in study done by Hala et al. ${ }^{[9]}$

Onset of motor block was found to be comparable in group C and group D and it was slightly prolonged in group F.(As shown in [Table $2 \&$ Figure 2].

Total duration of motor block was found to be markedly increased in group D $(369 \pm 25)$ as compared to both group $\mathrm{C}(130.2 \pm 9.5)$ and group $\mathrm{F}(230 \pm 26.6) \quad$ [Figure $1 \&$ Table 2]

Al-Mustafa-et al, ${ }^{[10]}$ and Al-Ghanen et al, ${ }^{[7]}$ used higher that its effect is dose dependent.

In a study done by Gupta et al, ${ }^{[11]}$ motor and sensory block was prolonged with addition of $5 \mu \mathrm{g}$ dexmedetomidine intrathecaly. The demand for post-operative analgesia was reduced in $24 \mathrm{hrs}$. It is in concordance with our study.

In our study we noted rescue analgesia was required much later in both group F $(250.3 \pm 24)$ and D $(443 \pm 32)$ group as compared to group C. $(156.5 \pm 13.2)$. Requirment of the rescue analgesia was markedly delayed in group D cases as compared to group $\mathrm{F}$ cases which support the analgesic efficacy of Dexmedetomidine as an adjuvant to bupivacaine. [Figure 3]

Similarly significant improved analgesic efficacy was seen by Gupta et al. ${ }^{[1]}$ Al-Mustafa et al, ${ }^{[10]}$ and Hala EA et al, ${ }^{[9]}$ compared Dexmedetomidine and fentanyl as intrathecal adjuvants ( $\mathrm{p}$ less then 0.001 ) and observed dose dependent prolongation of motor and sensory blockade with reduced analgesic requirement with increasing doses of intrathecal Dexmedetomidine $(5,10$, and $15 \mu \mathrm{gm})$

\section{Conclusion}

In conclusion, Intrathecal Dexmedetomidine used as an adjuvant to bupivacaine in spinal block seems to be a good alternative to intrathecal fentanyl as it produces early onset and prolonged duration of sensory and motor block without significant haemodynamic alteration and side effects. It also produces excellent quality of post-operative analgesia.

\section{References}

1. Chavan G, Chavan A, Ghosh A. Effect of intrathecal fentanyl on subarachnoid block with $0.5 \%$ hyperbaric bupivacaine .InternationalJ.of healthcare and biomedical research.2014;2(4):67-76.

2. Shaikh S, Dattatri R. Dexmedetomidine as an adjuvant to hyperbaric spinal bupivacaine for infraumblical procedures :A dose related study. Anaesth Pain and Intensive Care 2014;18(2):180-85.

3. Bromage PR.A comparision of the hydrochloride and carbondioxide salt of lidocain and prilocain in epidural analgesia, Acta Anaesthesiol Scand1965;16:55-69.

4. Wewers ME, Lowe NK. A critical review of visual analogue scales in the measurement of clinical phenomena. Res Nurs Health 1990Aug;13(4):227-36

5. Ishii H, Kohno T, Yamakura T, Ikoma M, Baba H. Action of Dexmedetomidine on Substantia gelatinosa neurons of the rat spinal cord. Eur J Neuro Sci 2008;27:3182 -90.

6. Mantz J, Josserand J,Hamada S. Dexmedetomidine:New insights. Eur J Anaesthesiol 2011Jan;28(1):3-6. [Pub Med]

7. Al Ghanem SM,Massad IM.Al Mustafa MM,Al- Zaben KR et al. Effect of adding Dexmedetomidine versus fentanyl to intrathecal bupivacain on spinal block characteristics in gynecological procedures:A double blind controlled study.Am J Appl Sci.2009;6(5):882-7.

8. Shukla D, Verma A, Agarwal A, Pandey HD. Comparative study of intrathecal Dexmedetomidine with intrathecal magnesium used as adjuvants to bupivacaine. J Anaesthesiol Clin Pharmacol 2011;27:4959.

9. Hala EA ,Shafie MA, Yousef H. Dose related prolongation of hyperbaric bupivacain spinal anaesthesia by Dexmedetomidine .Ain Shams J Anaesthesiol 2011;4:83-95.

10. Al- Mustafa MM, Abu-Halaweh SA, Aloweidi AS, Murshidi MM et al. Effect of Dexmedetomidine added to spinal bupivacaine for urological procedures.Saudi Med J 2009;30:365-70. [Pub Med]

11. Gupta R, Verma R ,Bogra J,Kohli M,Raman R,Kushwaha JK.A comparative study of intrathecal dexmedetomidine and fentanyl as adjuvants to bupivacain.J Anaesthesiol Clin Pharmacol 201;27:339-43. 
0

Copyright: (c) the author(s), publisher. Academia Anesthesiologica International is an Official Publication of "Society for Health Care \& Research Development". It is an open-access article distributed under the terms of the Creative Commons Attribution Non-Commercial License, which permits unrestricted non-commercial use, distribution, and reproduction in any medium, provided the original work is properly cited.

How to cite this article: Saxena AK, Singh S, Mathur BL, Rungta N. Comparative Evaluation of Intrathecal Dexmedetomidine and Fentanyl with Hyperbaric Bupivacaine for Post-Operative Analgesia in Lower Abdominal Surgeries. Acad. Anesthesiol. Int. 2019;4(2):193-96.

DOI: dx.doi.org/10.21276/aan.2019.4.2.44

Source of Support: Nil, Conflict of Interest: None declared. 